\title{
Sobre las traducciones al español de los antropónimos en el relato de Chejov Apellidos de caballo
}

\author{
Kirill KorkonósenKo, Roberto Monforte DuPRET \\ Academia de Ciencias de Rusia, Universidad del País Vasco \\ korkonos@yandex.ru; robertovicente.monforte@ehu.es
}

Recibido: Diciembre de 2010

Aceptado: Febrero de 2011

\begin{abstract}
Resumen
El objetivo del presente artículo es estudiar las diferentes traducciones al español de los apellidos que aparecen en el relato de Chéjov Apellido de caballo, así como analizar los problemas traductológicos que se derivan de su carácter cómico y calambúrico.
\end{abstract}

Palabras clave: Literatura rusa, traducción, lengua española, Chéjov.

\begin{abstract}
Abstract:This paper examines Spanish translations of surnames that appear in Chekhov's story Horse Surname, as well as analyzes the problems arising from his comical character and puns.
\end{abstract}

About Spanish Traslations of Family Names in Chekhov's tale Horse Surname

Key words: Russian Literature, Traslation, Spanish, Chekhov.

En el presente artículo estudiaremos las diferentes variantes en la traducción al español de los cómicos apellidos del relato de Chéjov Apellido de Caballo ${ }^{1}$. Los motivos que nos han llevado a escoger este relato de Chéjov son, principalmente, dos: por un lado, su palpable comicidad y carácter calambúrico (lo que complica la labor del traductor, pues aquello que resulta gracioso en ruso y para los rusos, también debería serlo para los hablantes de otra lengua) y, por otro lado, la existencia de suficientes versiones en español para la realización de un análisis pormenorizado. Para este trabajo nos hemos servido principalmente de tres traducciones españolas de Apellido de caballo (las tres portan el mismo título), las cuales se reeditaron en repetidas ocasiones lo que, de forma indirecta, refrenda la "calidad" de las mismas $y$, hasta cierto punto, demuestra su buena acogida en la cultura española. Además,

${ }^{1}$ No nos ha resultado posible utilizar otras versiones de Apellido de caballo. 
los tres traductores son estudiosos de la literatura rusa y promotores de la cultura rusa en el mundo hispanoparlante y sus versiones, en cierto modo, reflejan claramente tres periodos de la recepción y difusión de la obra chejoviana en España. Nos referimos, en primer lugar, a la traducción de Portnoff que se sitúa cronológicamente en los albores de la llegada de la obra literaria de Chéjov a España; a continuación, la traducción de Zernask que nos remite a un momento en que Chéjov ya se encontraba bastante bien afianzado en España, pero cuya difusión todavía dependía en gran medida de los traductores extranjeros y por último tenemos la traducción de Gallego Ballestero que forma parte del corpus más moderno de traducciones de la obra chejoviana, ya realizada por traductores nativos.

La variante más temprana, como hemos dicho, pertenece a George Portnoff y data del año 19242 . Portnoff "uno de los primeros investigadores de la influencia de la literatura rusa en las letras españolas"3, era un emigrante ruso que vivió primero en España, donde trabajó como traductor y profesor de ruso en el Ateneo de Madrid y entabló gran amistad con la escritora María Martínez Sierra, y posteriormente emigró a los Estados Unidos donde murió. Portnoff tradujo al español en la década de los años 20 del siglo XX más de 50 obras de autores rusos entre los que se encuentran Avérchenko, Andréiev, Artybashev, Gógol, Gorki, Kuprín, Lérmontov, Pushkin, L.N. Tolstói, Turguénev, Chéjov. Su monografía La literatura rusa en España (New York, Instituto de las Españas, 1932) sigue conservando su valor científico y se cita en numerosos trabajos dedicados a la literatura comparada.

La información biográfica que se puede obtener sobre los otros traductores es considerablemente menor. Heino Zernask (a juzgar por su nombre y apellido posiblemente se trate de un traductor de origen estonio) publicó en 1975 sus traducciones en la recopilación Cuentos de Chéjov. Su antología El beso y otros relatos se publicó por primera vez en España en 1980 y desde el año $2000^{4}$ se ha reimpreso en varias ocasiones $(2001,2004)$, siempre en la editorial Edasha. Zernask es también es autor de la monografía dedicada a Chéjov El otro jardín: Vida y obra de Anton Chéjov (Buenos Aires, Eudeba, 1986).Resulta curioso que sólo la traducción de Apellido de caballo realizada por Zernask, se puede encontrar, no sin esfuerzo, en internet.

Víctor Gallego Ballestero comenzó a traducir autores rusos en los años 90 y consiguió que los lectores españoles trabaran conocimiento con muchas obras literarias rusas que anteriormente les eran inaccesibles. Su nómina de traducciones presenta obras de Herzen, Goncharov, Bunin, L.N. Tosltói, Pasternak o Pushkin. Además es autor de las traducciones de Cartas a Stalin de Bulgákov, Cartas del lejano oriente y de las Islas Solovki de P. Florenski, así como nuevas versiones del Diario de un escritor de Dostoievski y de Humo de Turguénev. Pero, sin lugar a dudas, Gallego Ballestero a quien más ha traducido ha sido a Chéjov, de hecho su versión de La isla de Sajalín es la primera que se ha realizado al español. En 2005 sus traducciones de

\footnotetext{
2 CHÉJOV, A.P. (1924): La cerilla sueca (trad. directa del ruso por G. Portnoff), Madrid, Calpe, p. 91-97.

3 АЛЕКСЕЕВ М. П. (1985): Русская культура и романский мир, Ленинград, с. 212.

${ }^{4}$ CHÉJOV, A.P. (2000): El beso y otros relatos (selección traducción y prólogo de Henio Zernask), Madrid, Edhasa. p. 219-223.
} 
los relatos de Chéjov fueron recogidas en el segundo tomo de las Obras completas (sic!) (Madrid, RBA, 2005) ${ }^{5}$. Asimismo, Gallego Ballestero se manifiesta también como un estudioso de la obra de Chéjov como demuestran los prólogos que preceden a sus traducciones, así como la pequeña biografía del autor que lleva por título Anton Pávlovich Chéjov (1860-1904) (Madrid, Del Orto, 1998).

A continuación, presentamos el análisis de las diferencias y analogías en la interpretación y traducción de los apellidos equinos que se ofrecen en las tres versiones homónimas del relato de Chéjov. Para mayor claridad, hemos creado una tabla donde aparecen tres columnas con las versiones de los apellidos de cada uno de los traductores. En negrita señalamos aquellas variantes que exigen un comentario más detallado.

\begin{tabular}{|c|c|c|c|}
\hline Чехов & Portnoff & Zernask & Gallego Ballestero \\
\hline Кобылин & caball & Cavallero & Potrov \\
\hline Жеребцов & potro / potrós & Alazano & Yeguóvich \\
\hline Жеребятников & potrito & Tordillo (серый) & Corcelóvich \\
\hline Кобылицын & yegual & Jaco & Caballeróvich \\
\hline Кобылятников & yeguaf & Jamelgo & Caballérov \\
\hline Кобелев & yeguales & Sabueso (ищейка) & Caballerinski \\
\hline Жеребчиков & potriñatof & Crin (грива) & Garañónov \\
\hline Лошадинин & caballín & Caballo & Caballinski \\
\hline Лошаков & caballás & Cavallo & Corcelinski \\
\hline Жеребкин & potronin & Cavalo & Potrinski \\
\hline Лошадкин & potránech & Casco & Caballónov \\
\hline Кобылкин & caballánech & Potro & Potrónov \\
\hline Коренной & - & Bayo & Trotónov \\
\hline Коренников & potrinin & Leoncavallo & Trotónovich \\
\hline Пристяжкин & yegüín/yegualín & Carreras (скачки) & Rocinóvich \\
\hline Жеребчиков & potritoff & Corcel & Corcelonski \\
\hline Жеребковский & potrikowsky & Cuadrúpedo & Corcelónov \\
\hline Жеребенко & potrocoff & Rocín (кляча) & Corcelov \\
\hline Лошадинский & caballoinsky & Yugo (ярмо) & Caballonovski \\
\hline Лошадевич & caballosoff & Cincha (подпруга) & Caballósov \\
\hline Жеребкович & potrikinin & Rienda & Yegüinski \\
\hline Кобылянский & yeguansky & - & Garañinski \\
\hline Конявский & jaco & Tropero (барышник) & Rocinski \\
\hline Лошадников & jacálaf & Anca(круп) & Caballúnov \\
\hline Табунов & cuadras & Tropilla(табун) & Yeguadóvich \\
\hline Копытин & casquín & Galope & Pezuñónov \\
\hline Жеребовский & yegualasín & Pezuña & Potronóvich \\
\hline Коненко & - & Overo (соловый) & Caballenko \\
\hline Конченко & - & Рío (чубарый) & Caballenkóvi \\
\hline Жеребеев & - & Zaino (гнедой) & Potrenko \\
\hline Кобылеев & - & - & Corcelenko \\
\hline Тройкин & rienda & Troikin & Calesovich \\
\hline Уздечкин & troikín & Cuadriga & Riendanenko \\
\hline
\end{tabular}

5 CHÉJOV A.P. (2005): Obras completas, t. 2, Madrid, RBA, p. 71-73. En el primer tomo (sólo hay dos tomos) se recoge la producción dramática de Chéjov. Las traducciones de este tomo corren a cargo de Antoni Puigròs Jaume y el estudio preliminar es obra de Sophie Lafitte. 


\begin{tabular}{|c|c|c|c|}
\hline Гнедов & alazán & Trotín & $\begin{array}{c}\text { Alazánov } \\
\text { Trotónov }\end{array}$ \\
\hline Рысистый & bауо & Montura (сбруя) & Jamelgóvich \\
\hline Лошадицкий & ruano (игреневый) & - & Castradóvich \\
\hline Меринов & corceloff & Pegaso & Bayonóvich \\
\hline Буланов & bayó/bayá & Remo (нога) & Arnesónov \\
\hline Чересседельников & lanza (копье, дышло) & Silla (ceдло) & Riendanóvich \\
\hline Засупонин & riendasa & Arnés & Jamelgónov \\
\hline Лошадский & caballosará & Recado (cбруя) & Avénov \\
\hline Овсов & avena & Avena & A \\
\hline
\end{tabular}

Si echamos un rápido vistazo a las columnas, enseguida advertimos que las traducciones no coinciden entre sí y no siempre concuerdan con los apellidos del original. En el texto de Portnoff los apellidos se escriben siempre en minúscula, exceptuando los casos en que se encuentran al principio de la frase. Aunque hoy en día todavía no existe un consenso unánime en España a la hora de transcribir el alfabeto cirílico, bien es verdad que la transcripción utilizada por Portnoff resulta anticuada y en buena parte influida por el sistema francés de transliteración ${ }^{6}$. Desde 1920 en España ha cambiado mucho la transcripción de los nombres propios, algo claramente observable en la transcripción actual de los apellidos rusos, en los que nunca se utiliza ni la $-\mathrm{w}$ - ni las terminaciones -off y -sky, sino que se ha normalizado el uso de la $-\mathrm{v}$ - y de las terminaciones en -ov y -ski.

Por otra parte, tanto Portnoff como Zernask se dejan sin traducir algunos apellidos, tan sólo Victor Gallego traduce todos.

Salta a la vista que los listados de Portnoff y Gallego Ballestero es más pobre que el de Chéjov y en general se valen de una reducida cantidad de raíces para formar sus apellidos. Sin embargo, estos dos traductores son los que procuran ceñirse lo máximo posible al lexema original de los apellidos, no ocurre lo mismo con Zernask que da rienda suelta a su fantasía, a veces demasiado, pues en su listado podemos encontrar apellidos realmente absurdos y, lo que es peor, totalmente ajenos al sistema lexemático de los apellidos originales (Leoncavallo, Cuadrúpedo, Cuádriga, Pegaso...). Además, también podemos observar que Zernask en su traducción utiliza palabras que realmente existen en lengua española y no realiza ningún esfuerzo por rusificarlos con alguna de las numerosas terminaciones propias de los apellidos rusos, algo que sí hacen Portnoff y, en muchísima mayor medida, Gallego Ballestero (Garañónov, Caballósov, potrinin, potrocoff...). No se sabe muy bien por qué Zernask realiza una excepción para el apellido Troikin, que nos remite a una palabra que desde ya hace bastante tiempo está arraigada en el léxico castellano (troika) y que posee dos significados: "gran trineo ruso tirado por tres caballos" y "equipo político constituido por tres personas. Generalmente referido a Rusia"7

\footnotetext{
${ }^{6}$ Algo que afectaría a su propio apellido, que actualmente debería transcribirse como Portnov.

7 SECO, M.; ANDRÉS, O.; RAMOS, G. (1999): Diccionario Del español actual, Madrid, Aguilar, t. 2, p. 4421.
} 
Por el contrario, con respecto al Kobeliov y la frase de Chéjov "a lo mejor es un apellido de perro y no de caballo", el único traductor capaz de transmitir el verdadero sentido del pasaje fue Zernask. La frase en la traducción de Portnoff está vertida de forma correcta, sin embargo el significado de la misma sigue remitiéndonos al mundo equino (yeguales) y no al canino, lo que resulta inexacto e imprime cierta incongruencia al texto. En su versión, Gallego Ballestero, al igual que Portnoff, sigue utilizando un apellido relacionado con el mundo ecuestre (Caballerinski) lo que de nuevo vuelve a ser incorrecto y poco coherente. En la traducción de Zernask, aparece el apellido Sabueso, que formalmente es correcto, pues en ruso Kobeliov procede de la palabra kobel (кобель-perro/can) у no kobyla (кобыла-уegua), de ahí que se le venga a la cabeza al personaje del relato la citada frase: "a lo mejor es un apellido de perro y no de caballo". El problema reside en que en español, por desgracia, no existe esa cercanía fonética entre las raíces que hacen referencia a "perro/can" (кобель) у а "уegua" (кобыла), lo que complica en gran medida encontrar una solución satisfactoria al problema ${ }^{8}$.

De la comparación de las traducciones se desprende que, probablemente, Gallego Ballestero haya utilizado la traducción de Portnoff como modelo, pues en su versión hay pequeñas modificaciones con respecto a las variantes que aparecen en la traducción de 1924 (cambio de terminaciones, distintos sistemas de transliteración:Caballosoff/Caballósov, Yeguanski/Yegüinski, Corceloff/Corcelov). A la traducción de Gallego Ballestero también se le puede reprochar la repetición del apellido Trotónov (en Chéjov no hay repeticiones). No obstante, es obligado mencionar que este traductor es el único que no teme traducir de forma correcta el apellido Mérinov: Castradóvich.

Al final del relato, Iván Evsevich se inventa unos apellidos completamente ajenos al idioma ruso: Cheressedélnikov y Zasuponin. Ninguno de los traductores es capaz de transmitir el matiz absurdo de estos apellidos que pretende refleja la angustia espiritual que envuelve al intendente en su desesperada búsqueda de un apellido relacionado con el mundo equino.

En conclusión, a partir de la comparación realizada, ninguna de las tres traducciones es ideal, sin embargo, cada una de ellas tiene sus virtudes. Por consiguiente, podemos decir que, en general, los traductores más o menos consiguen arreglárselas bastante bien con la difícil tarea de traducir este relato, bien es verdad que no de forma brillante, pero al menos sí satisfactoriamente, lo que una vez más demuestra la capital importancia de la traducibilidad del juego de palabras para obtener una buena traducción. Puede ser que al lector español no versado en el idioma ruso le sea muy recomendable familiarizarse con este relato a través de dos o incluso de las tres traducciones, de las que resulta muy difícil decidir cuál es mejor.

\footnotetext{
8 Las soluciones que proponemos, lejos de ser las mejores, comprenderían la utilización de los apellidos Podencov (podenco) por su similitud con, por ejemplo, Potrancov (potranco) o, por otro lado, el trasladado de la esfera de la confusión al mundo de las aves, utilizando el apellido Polleznov (pollezno) por su similitud con, por ejemplo, Pollinov (pollino).
} 


\section{Referencias bibliográficas}

AA.VV. (2005): Pequeño Larousse ilustrado, Spes Editorial, Barcelona, p. 1003.

CHÉJOV, A.P. (1924): La cerilla sueca (trad. directa del ruso por G. Portnoff), Calpe,Madrid, p. 91-97.

CHÉJOV, A.P. (1975): Cuentos de Chéjov, Ediciones Peronio, Barcelona, p. 235-238.

CHÉJOV, A.P. (2000): El beso y otros relatos (selección traducción y prólogo de Henio Zernask), Edhasa, Madrid, p. 219-223

CHÉJOV A.P. (2005): Obras completas (introducción y traducción de Víctor Gallego Ballestero), t. 2, RBA, Madrid, p. 71-73.

GAllego BAlleSterO, V. (1998): Anton Pávlovich Chéjov (1860-1904), Del Orto, Madrid.

PORTNOFF, G. (1932): La literatura rusa en España, Instituto de las Españas, New York.

SECO, M.; ANDRÉS, O.; RAMOS, G. (1999): Diccionario Del español actual, Aguilar, Madrid, t. 2, p. 4421.

ZERNASK, H. (1986): El otro jardín: Vida y obra de Anton Chéjov, Eudeba, Buenos Aires.

АЛЕКСЕЕВ М. П. (1985): Русская культура и романский мир, Наука, Ленинград, p. 212. 